\section{Report released on antibiotic resistance}

The Wellcome Trust today releases a report to inform the United Nations General Assembly's High-level Meeting on Antimicrobial Resistance later this month (see www.wellcome. ac.uk/drugresistantinfections). The report distils the findings of an international summit of researchers, policymakers and multilateral institutions that met in London in April 2016.

It identifies three areas for immediate action to alleviate the current and future impact of drug-resistant infections on the number of deaths and on national economies. The summit and report build on the independent review on antimicrobial resistance led by economist Jim O'Neill and commissioned by the UK government, in partnership with the Wellcome Trust, which was published in May 2016 (see go.nature.com/2bsxoyi). Together, these reports should help to focus attention and galvanize support from national governments, the G7 and G20 countries, international agencies and nongovernmental organizations.

The UN resolution on antimicrobial resistance should commit governments and international organizations to concerted and verifiable action, adapted locally as necessary. Continued support for scientific research and innovation is essential to shape future responses, but the need for further research must not be an excuse for delaying urgent interventions.

Jeremy Farrar Wellcome Trust, London.

Sally Davies Department of Health, London.

j.farrar@wellcome.ac.uk

\section{Antibiotic partners promote discovery}

As president of the Infectious Diseases Society of America and a physician of infectious diseases, I am greatly encouraged by the launch of the Combating Antibiotic Resistant Bacteria Biopharmaceutical Accelerator (CARB-X; see Nature http:// doi.org/bp7x; 2016). Contrary to your implication, this public-private partnership is designed to foster antibiotic discovery as well as preclinical antibiotic development (see www.carb-x.org). Physicians who treat the increasing numbers of people with infections caused by multidrug-resistant organisms know at first hand the urgent need for novel antibiotics.

Most pharmaceutical companies have been retreating from antibiotic research and development (R\&D) over the past few decades because of economic, regulatory and scientific hurdles. Fresh incentives are needed to stimulate and support all stages of antibiotic R\&D if new drugs are to be discovered and brought to market in a timely fashion. CARB-X can play an important part in this broader effort, which must also include other economic and regulatory incentives that are currently under consideration in the US Congress.

Johan S. Bakken St. Luke's Medical Center, Duluth, Minnesota, USA.

jbakken1@d.umn.edu

\section{Brexit threatens China collaboration}

Brexit - Britain's exit from the European Union - threatens to undermine the country's scientific relationships with nations outside the EU (see E. Masood Nature 535, 467; 2016). The country will need to invest more to maintain its valuable collaboration with China, for example, once EU funding is withdrawn.

The United Kingdom could be excluded from exchanges under the EU's Marie SkłodowskaCurie fellowship programme, which have benefited thousands of talented Chinese and British scientists since 2007. For the country to retain its current exchange level of international research talent, it would need to invest more in its Newton Fund to make up the shortfall (see go.nature.com/2bfgzq3).

Also under threat will be British scientists' participation in China's projects with the EU, such as its Five-hundred-meter Aperture Spherical Telescope, due to be completed this year (see W. Yang Nature 534, 467-469; 2016).

Despite such uncertainties, Brexit could still provide opportunities to strengthen scientific collaboration between the world's second and fifth largest economies - for example, through the collaboration between Research Councils UK and the National Natural Science Foundation of China (see go.nature.com/2bflysi).

Hong Yang Norwegian Institute of Bioeconomy Research; and University of Oslo, Norway. Roger J. Flower University College London, UK.

Xianjin Huang Nanjing

University, China.

hongyanghy@gmail.com

\section{Gap widens for honorary PhDs}

The changing nature of the standard $\mathrm{PhD}$ degree (Nature 535, 26-28; 2016) could make the honorary $\mathrm{PhD}$ seem increasingly hollow by comparison.

Universities confer honorary doctorates on those who have attained national or international prominence in the arts, sciences or sporting fields. Scholarly skills are rarely considered, although most recipients have sufficient expert knowledge to potentially write a thesis. Recipients often have links with the awarding institute, which benefits from the associated publicity.

By contrast, the standard $\mathrm{PhD}$ is awarded in recognition of research expertise. Now that more $\mathrm{PhD}$ graduates pursue careers outside academia, programmes are placing greater emphasis on transferable scholarly skills and on developing management, entrepreneurship and teamwork skills. These additional training requirements threaten to stoke academic tensions over the existing gap in scholarship between standard and honorary PhDs.

Steven Watterson University of

Ulster, Londonderry, UK. s.watterson@ulster.ac.uk.

\section{Bite like a spider, sting like a scorpion}

The image of a togo starburst tarantula (Heteroscodra maculata) on your Contents page in the print issue (Nature 534, $433 ; 2016)$ is incorrectly titled 'Sting like a spider'. Spiders do not sting, they bite.

Arthropod bites and stings are differentiated by the nature and purpose of the stinging or biting apparatus, and by their clinical effects (see J. Goddard Physician's Guide to Arthropods of Medical Importance; CRC Press, 2012). Bees and scorpions, for example, inject their stings mainly for defence; spiders bite usually to immobilize or kill their prey, by injecting venom from their fangs. These insults typically result in one or two puncture marks, respectively, in the victim's skin, serving as useful indicators for diagnosis and treatment.

Reza Afshari $B C$ Centre for Disease Control, Vancouver, Canada. reza.afshari@bccdc.ca

\section{CONTRIBUTIONS}

Correspondence may be submitted to correspondence@nature. com after consulting the author guidelines at http://go.nature.com/ cmchno. 